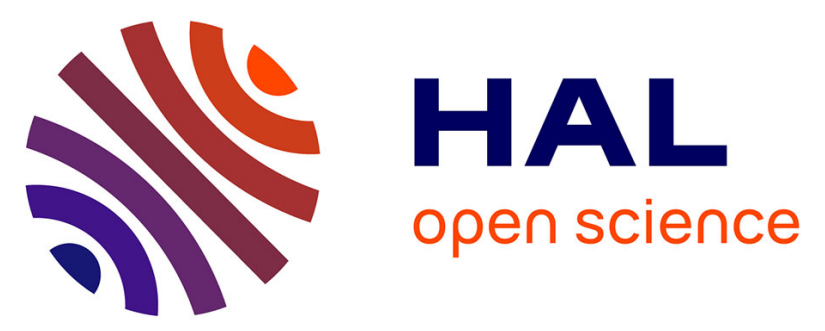

\title{
2d granular gas in Knudsen regime and in microgravity excited by vibration: velocity and position distributions
}

\author{
M. Hou, R. Liu, Y. Li, K. Lu, Yves Garrabos, Pierre Evesque
}

\section{To cite this version:}

M. Hou, R. Liu, Y. Li, K. Lu, Yves Garrabos, et al.. 2d granular gas in Knudsen regime and in microgravity excited by vibration: velocity and position distributions. Powders and Grains 2009: proceedings of the 6th International Conference on Micromechanics of Granular Media, Jul 2009, Golden (Colorado), United States. pp.67-70, 10.1063/1.3180018 . hal-03266232

\section{HAL Id: hal-03266232 \\ https://hal.science/hal-03266232}

Submitted on 21 Jun 2021

HAL is a multi-disciplinary open access archive for the deposit and dissemination of scientific research documents, whether they are published or not. The documents may come from teaching and research institutions in France or abroad, or from public or private research centers.
L'archive ouverte pluridisciplinaire HAL, est destinée au dépôt et à la diffusion de documents scientifiques de niveau recherche, publiés ou non, émanant des établissements d'enseignement et de recherche français ou étrangers, des laboratoires publics ou privés. 


\section{2d Granular Gas in Knudsen Regime and in Microgravity Excited by Vibration: Velocity and Position Distributions}

Cite as: AIP Conference Proceedings 1145, 67 (2009); https://doi.org/10.1063/1.3180018

Published Online: 01 July 2009

M. Hou, R. Liu, Y. Li, K. Lu, Y. Garrabos, and P. Evesque

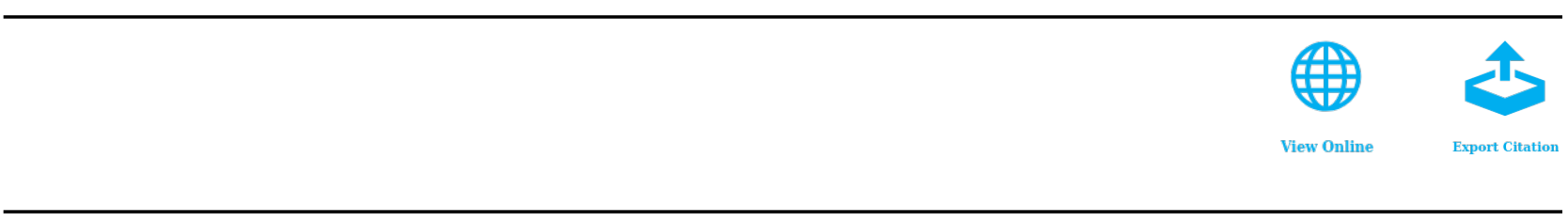

\section{Conference Proceedings}

Get $30 \%$ off all print proceedings! 


\title{
2d Granular Gas in Knudsen Regime and in Microgravity Excited by Vibration: Velocity and Position Distributions
}

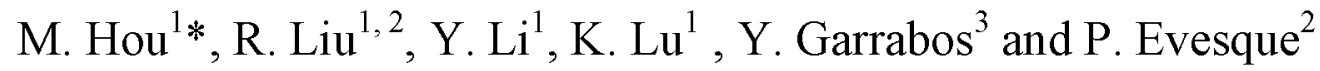 \\ ${ }^{1}$ Beijing National Laboratory for Condensed Matter Physics, Institute of Physics, Chinese Academy of Sciences, \\ Beijing, China 100080 \\ ${ }^{2}$ Lab MSSMat, UMR 8579 CNRS, Ecole Centrale Paris, 92295 CHATENAY-MALABRY, France \\ ${ }^{3}$ ESEME-ICMCB, UPR 9048 CNRS, Univerité Bordeaux 1, 33608 PESSAC France
}

\begin{abstract}
Dynamics of quasi-2d dissipative granular gas is studied in microgravity condition (of the order of $10^{-4} \mathrm{~g}$ ) in the limit of Knudsen regime. The gas, made of 4 spheres, is confined in a square cell enforced to follow linear sinusoidal vibration in ten different vibration modes. The trajectory of one of the particles is tracked and reconstructed from the 2hour video data. From statistical analysis, we find that (i) loss due to wall friction is small, (ii) trajectory looks ergodic in space, and (iii) distribution $\rho(v)$ of speed follows an exponential distribution, i.e. $\rho(v) \approx \exp \left(-\mathrm{v} / \mathrm{v}_{\mathrm{xo}, \mathrm{yo}}\right)$, with $\mathrm{v}_{\mathrm{xo}, \mathrm{yo}}$ being a characteristic velocity along a direction parallel $(\mathrm{y})$ or perpendicular $(\mathrm{x})$ to vibration direction. This law deviates strongly from the Boltzmann distribution of speed in molecular gas. Comparisons of this result with previous measurements in earth environment, and what was found in $3 \mathrm{~d}$ cell [1] performed in $10^{-2} \mathrm{~g}$ environment are given.
\end{abstract}

Keywords: Granular Gas, speed distribution, ergodicity, microgravity, vibration.

PACS: 04.80.-y , 05.20.Dd, 05.40.-a, 81.20.Ev, 87.16.dj, 82.70.-y, 83.80.Fg, 83.10.Pp

\section{INTRODUCTION}

The behavior of granular matter in micro-gravity has been studied only very recently (1998) [2], while it was simulated a little earlier [3] with different kinds of computing programs [4-6]. Despite its fundamental aspect, the acquisition of this knowledge is of major challenge as soon as man will like to stay traveling far from the earth through long term journey because most human activities manipulate grains at some stage.

The first $0 \mathrm{~g}$ experiments on granular media were to test essentially samples with a small feeding ratio, from 1 grain to a few hundreds, in a cell which was agitated according to sinusoidal mechanical vibration. The physics addressed is that of a gas system, which dissipates energy during collisions, and needs continuous excitation so as for the system not to freeze. From the viewpoint of statistical mechanics, this dissipation is not a classic situation, and may produce important changes of behavior compared to the classic gas of molecules. Indeed, these microgravity experiments have produced some non classic behaviors $[1,2,7]$, which were not predicted by simulation or by theory [4-6]. For instance two of them particularly interest us in the present paper: (i) the non ergodic behavior of the dissipative-billiard played with 1 or 2 balls [7], for which one has found periodic bouncing solutions with an important reduction of the efficient phase space (from 13d to 1d); (ii) non classic distribution of speed of a dilute gas system [1] when the mean free path $l_{c}$ of the particle becomes of the order of the cell size. A non-Boltzmann speed distribution at impact with the immobile wall is found. It instead follows $\exp \left(-\mathrm{v} / \mathrm{v}_{\mathrm{o}}\right)$ law with $\mathrm{v}_{\mathrm{o}}$ proportional to the typical piston speed $\mathrm{b} \omega$ and scales as $\mathrm{N}^{-0.4}[1,8]$, where $\mathrm{N}$ is the total number of balls.

In this paper, we pursue this investigation with the case of a quasi-2d dissipative gas in a low density regime and excited by sinusoidal shaking along a certain direction in microgravity (of the order of $10^{-}$ ${ }^{4} \mathrm{~g}$ ). Movement of one particle in a cell of 4 moving particles is video recorded for 2 hours in ten different vibration modes. The particle trajectory is traced and analyzed, and its velocity distribution is drawn for each vibration mode. We expect a velocity distribution close to Maxwell-Boltzmann distribution, $\exp \left(-\mathrm{v}^{2} / \mathrm{v}_{\mathrm{o}}{ }^{2}\right)$ , as in gas phase. It is, however, found that the velocity distribution in either $\mathrm{y}$ or $\mathrm{x}$ direction is an exponential function of $\mathrm{v}, \exp \left(-\mathrm{v} / \mathrm{v}_{\mathrm{io}}\right)$, but with different characteristic velocities $\mathrm{v}_{\mathrm{xo}}, \mathrm{v}_{\mathrm{yo}}$, which are linearly proportional to the maximum vibration velocity $\mathrm{v}_{\mathrm{b}}=$ $\mathrm{b} \omega$ (where $\mathrm{b}$ is the vibration amplitude and $\omega$ is the angular velocity of the cell).

Simulations [11] and experimental studies [12, 13] 
published so far find the velocity distributions of granular gases are of the form $\exp \left(-\left(\mathrm{v} / \mathrm{v}_{\mathrm{o}}\right)^{\alpha}\right)$ with $\alpha$ varies from 1 to 2 depending on the restitution coefficient of particles, the friction of particles with the cell walls, number of particles in the system, and if rotation and gravity are taken into consideration. In our case the experiments are performed in microgravity, friction caused by the lateral walls is not significant, and although the only attaching force is given by the vibrating wall in $y$ direction, particle motions seem ergodic that they occupy randomly all the accessible area in the cell. Presumably one would expect a velocity distribution closer to Gaussian that $\alpha$ is closer to 2. Our experimental findings, however, show a velocity distribution with a value of $\alpha \approx 1$. This exponential dependence is similar to what is obtained previously in $3 d$ cell [1] in Knudsen regime in parabolic flight experiments, but different by a prefactor $1 / \mathrm{v}$.

TABLE I. The vibration amplitude $b$, frequency $f=\omega$ $(2 \pi), \mathrm{v}_{\mathrm{b}},=\mathrm{b} \omega$ duration $\mathrm{T}$ of each mode, and the $\mathrm{v}_{\mathrm{yo}}$ obtained from fitting the ball velocity during each mode are listed for the 10 vibration modes.

\begin{tabular}{|c|c|c|c|c|c|}
\hline $\begin{array}{c}\text { Mode } \\
\#\end{array}$ & $\begin{array}{c}b \\
(\mathbf{m m})\end{array}$ & $f$ & $v_{b}$ & $\begin{array}{c}\text { Duration } \\
\mathbf{T}(\mathbf{s})\end{array}$ & $\begin{array}{c}\mathrm{V}_{\text {yo }} \\
(\mathbf{m m} / \mathbf{s})\end{array}$ \\
\hline 1 & 0.31 & 1.5 & 2.94 & 1261 & 2.62 \\
\hline 2 & 0.59 & 1.5 & 5.58 & 1263 & 4.83 \\
\hline 3 & 0.87 & 1.5 & 8.22 & 631 & 7.77 \\
\hline 4 & 0.4 & 3 & 7.54 & 630 & 6.74 \\
\hline 5 & 0.59 & 3 & 11.16 & 631 & 9.94 \\
\hline 6 & 0.70 & 3 & 13.27 & 631 & 10.42 \\
\hline 7 & 0.77 & 3 & 14.48 & 630 & 10.00 \\
\hline 8 & 0.19 & 6 & 7.24 & 631 & 6.17 \\
\hline 9 & 0.38 & 6 & 14.48 & 631 & 10.45 \\
\hline 10 & 0.22 & 10 & 14.07 & 629 & 9.88 \\
\hline
\end{tabular}

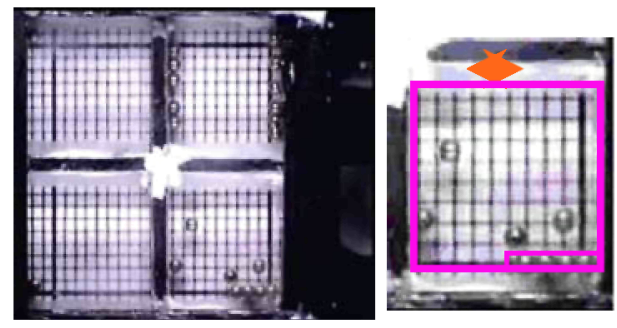

FIGURE 1. Left: a snapshot of the 4 cells; right: the moving balls in the studied cell.

\section{EXPERIMENTAL RESULTS}

The experiment was carried out in Satellite SJ-8 launched in September 2006. The $100 \mathrm{~mm}^{2}$ square cell is filled with 4 freely moving bronze spheres (diameter $\mathrm{d}=1.21 \pm 0.02 \mathrm{~mm}$ ) and 4 others, which are glued along the bottom side near the right corner so that the cell shape can not be considered as a square (see Fig. 1). The 4 side walls of the cell are in bronze, and the cell is closed by two sapphire windows that allows lighting, viewing and video recording, and are separated by $\delta=\mathrm{d}+0.1 \mathrm{~mm}$ so that ball rotation is allowed in the 3 directions, while translation motion of freely moving balls is essentially $2 d$. Vibration is imposed by the vibrator at the pre-programmed amplitude $b$ and frequency $f=\omega /(2 \pi)$ for a duration T; parameters are pre-coded to impose the series of parameters $\left(\mathrm{b}_{\mathrm{k}}, f_{\mathrm{k}}, T_{\mathrm{k}}\right)$ listed up in Table 1 with typical maximum speed $2.9 \mathrm{~mm} / \mathrm{s} \leq 2 \pi \mathrm{b}_{\mathrm{k}} \mathrm{f}_{\mathrm{k}} \leq 14.5 \mathrm{~mm} / \mathrm{s}$. The details of the experimental process can be found in the previous paper [14].

The imposed sinusoidal vibration excites the balls slow enough that a video camera of 25 frames per second can follow the ball motion. Ball position is therefore tracked at each video image and its trajectory is reconstructed, in pixel unit. Information on ball speed components can then be determined within an error of the order of 1 pixel/frame, i.e. $2.8 \mathrm{~mm} / \mathrm{s}$. Distributions of particle number density along $\mathrm{x}$ and $\mathrm{y}$ directions averaged within 5, 10 and 17 minutes is also performed for testing ergodicity of the trajectory.

Fig. 2 reports density distribution in mode 2, as an example, along $\mathrm{y}$ direction (left) and $\mathrm{x}$ direction (right), where $\mathrm{y}(\mathrm{x})$ is the direction parallel (perpendicular) to the direction of vibration. The most likely accessible region in y direction for the ball is from $(2 b+r)$ to $(L-r)$ if the farthest location the wall can go to the left is set to be $y=0$, where $L$ is the length of the cell, and $r$ is the ball radius. The four glued bronze balls at the left $1 \mathrm{~mm}$ of the $\mathrm{x}$ axis cause the lower probability of ball accessing to the area. It is shown that the ball fills all the possible accessible area in the cell. One can therefore conclude that ball evolves ergodic after a number of collisions since no location is more probable than another within fluctuation

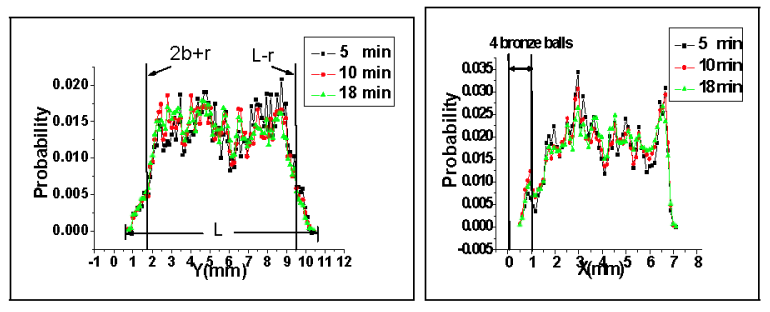

FIGURE 2. Ergodicity studied using ball trajectory data in mode 2. Distributions of particle number density, averaged within 5,10 and 18 minutes are plotted along y (left) and $\mathrm{x}$ direction (right). The farthest location the wall to the left is set to be $y=0$. The four glued bronze balls are located at the left of the $\mathrm{x}$ axis.

Figure 3 shows, as a typical example, the traced trajectory of a ball along the vibration direction for 
mode 1 excitation in unit of pixel per frame. As most of the local trajectories are linear, it tells us that the ball goes in the same direction for a few frames (within the experimental uncertainty) before it changes direction. This indicates the effect of lateral friction is small because otherwise the trajectory shall be curved due to a progressive change of speed caused by the wall friction. It shows that the main evolution of the speed is linked to collisions.

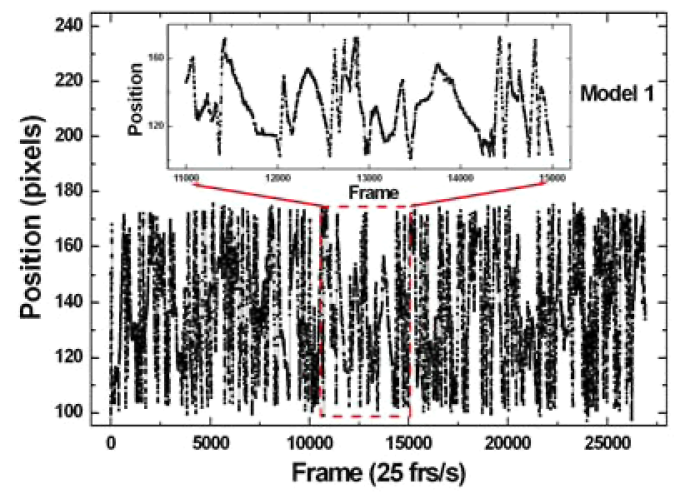

FIGURE 3. The trajectory of the ball in mode 1 is traced in unit of pixel per frame. In this figure as a demonstration only the traced trajectory of a single ball in y direction is shown.

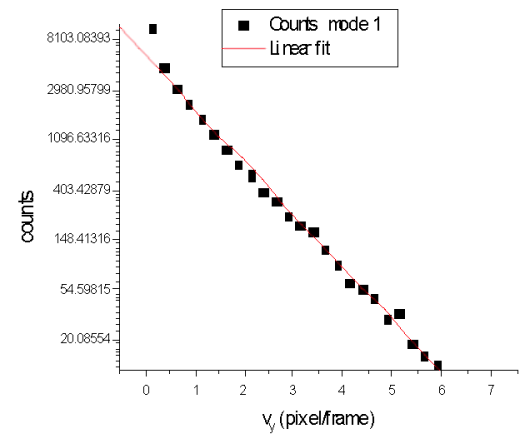

FIGURE 4. Velocity distribution in y direction for mode 1.
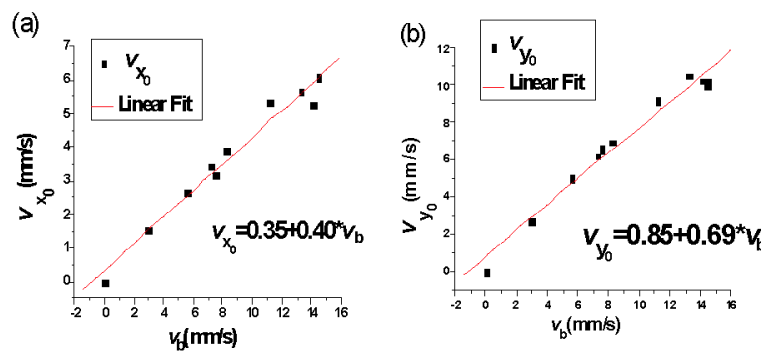

FIGURE 5. The characteristic velocities $\mathbf{v}_{\mathbf{x} 0}$ and $\mathbf{v}_{\mathbf{y}}$ versus the vibration velocity $\mathbf{v}_{\mathbf{b}}$ : (a) component perpendicular to the vibration direction, (b) component along vibration direction.

The probability distribution $\rho\left(v_{x, y}\right)$ of speed $v_{x, y}$ can be obtained from counting the number of times $\mathrm{N}(\mathrm{v})$ the ball has a speed in between $v_{x, y}$ and $v_{x, y}+\Delta v$, where $\Delta \mathrm{v}$ being fixed, leading to $\rho\left(\mathrm{v}_{\mathrm{x}, \mathrm{y}}\right) \Delta \mathrm{v}=$ $\mathrm{N}(\mathrm{v}) \Delta \mathrm{v} /\left[\int \mathrm{N}(\mathrm{v}) \Delta \mathrm{v}\right]$. A typical example is given in Figure 4 for the y component of mode- 1 excitation. One sees that the distribution is linear in a semi-log plot, indicating an $\exp \left(-\mathrm{v} / \mathrm{v}_{\mathrm{yo}}\right)$ distribution. Performing the same treatment and analysis for each mode and for both $\mathrm{x}$ and $\mathrm{y}$ directions, we have found similar exp($\mathrm{v} / \mathrm{v}_{\mathrm{xo}, \mathrm{yo}}$ ) exponential trends, each with a mean speed $\mathrm{v}_{\mathrm{xo}, \mathrm{y}}$; These characteristic velocities are found to be linearly dependent on $\mathrm{v}_{\mathrm{b}}$ as shown in Fig. 5 and the relationships are found: $\mathrm{v}_{\mathrm{xo}}=0.35+0.40 \mathrm{~V}_{\mathrm{b}}$, and $\mathrm{v}_{\mathrm{yo}}=$ $0.85+0.69 \mathrm{~V}_{\mathrm{b}}$, with constants in $\mathrm{mm}$.
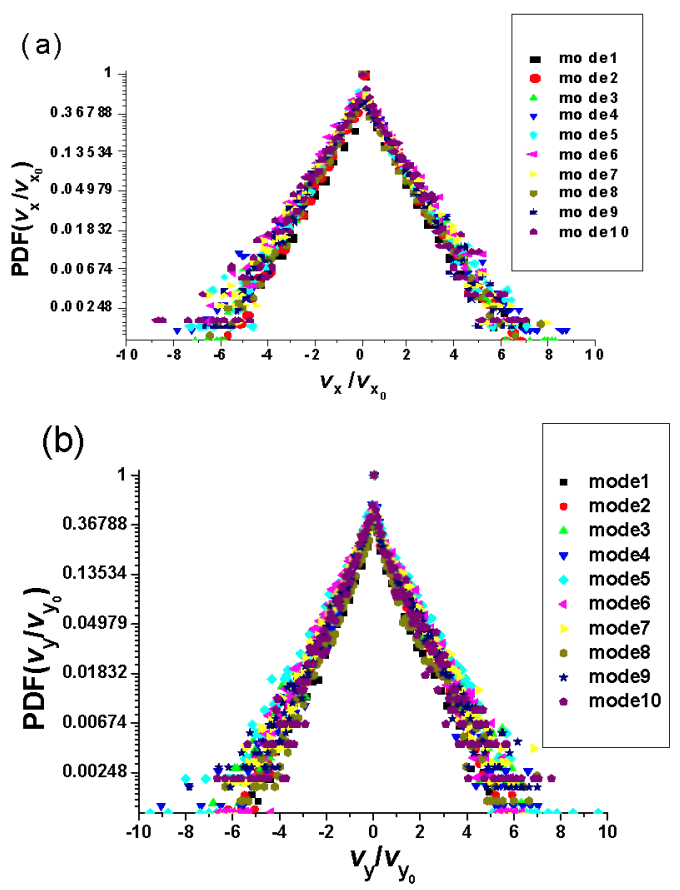

FIGURE 6. Probability density functions of (a) $\rho\left(v_{\mathrm{x}} / v_{\mathrm{xo}}\right)$ and (b) $\rho\left(v_{y} / v_{y o}\right)$ in rescaled units. Variations of $v_{x o}$ and $v_{y o}$ versus $b \omega$ are given in Fig. 5 .

As the mean values vary with the mode, the distributions can be rescaled to study whether the speed distribution depends on the mode. This is done in Fig. 6a and $6 \mathrm{~b}$ for $\mathrm{v}_{\mathrm{x}} / \mathrm{v}_{\mathrm{xo}}$ and $\mathrm{v}_{\mathrm{y}} / \mathrm{v}_{\mathrm{yo}}$ respectively. Curves exhibit a good overlapping, which indicates a unique distribution for $v_{x}$ and $v_{y}$. The $v_{x} \& v_{x}$ distributions look slightly different, since $\rho\left(v_{y}\right)$ is steeper at slow $\mathrm{V}_{\mathrm{y}} / \mathrm{v}_{\mathrm{yo}}$, which can be concluded from the slight curvature at small speed which is less pronounced for $\rho\left(\mathrm{v}_{\mathrm{x}}\right)$.

At last to confirm the little importance of the solid friction, we have investigated the dependence of the local mean speed in some direction as a function of the location. For instance, if the loss due to friction is 
large, one should expect a mean speed $\underline{v}^{+}$yo at $\mathrm{b}$ when ball is moving towards the direction $+y$ to be larger than the mean speed $\underline{\mathbf{v}}^{+}$yo at $\mathrm{L}-\mathrm{b}$ in the same $+\mathrm{y}$ direction, where $\mathrm{L}$ is the size of the cell. The difference between the distributions $\rho\left(v^{+}, y=b\right)$ and $\rho\left(\mathrm{v}^{+}, \mathrm{y}=\mathrm{L}-\mathrm{b}\right)$ shall give the losses during the travel from $b$ to L-b. By averaging the 10 modes the difference of the mean speed is found to be quite small $(6.8 \pm 1.8) \mathrm{mm} / \mathrm{s}-(6.2 \pm 1.4) \mathrm{mm} / \mathrm{s}$, i.e. inside the error bar.

\section{DISCUSSION AND CONCLUSION}

An important parameter in statistical analysis of a gas of particles is the mean free path that a particle can perform in between two collisions. In the present case, the cell size and the number of balls are small so that one has to take finite-size effects into consideration to calculate $l c$. This is done using the effective cell length $L$ eff $=L-d$ instead of $L$, and the effective number of balls $N$ eff which can collide with a given ball, i.e. $N$ eff $=$ $(\mathrm{N}-1)$. So $l_{c}$ satisfies $N_{\text {eff }} 2 d l_{c} /\left(L_{e f f}\right)^{2}=1$, which gives $l_{c}$ $=(L-d)^{2}[2 d(N-1)]$. Since $N=4, d=1.21 \mathrm{~mm}$, and $L=10 \mathrm{~mm}$, one gets $l_{c}=11 \mathrm{~mm}=1.2(L-d)$. As $l_{c}$ is larger than the effective cell size, the system is in the range of the Knudsen regime, that particles cannot be considered as only connected to the boundaries, but are also weakly coupled.

This situation is analogous to the one which has been studied during Airbus parabolic flights [1, 8] with 12 to 48 balls in a fixed cylindrical container with a vibrating piston, where the distribution $p(v)$ of the impacts of balls at speed with a fix gauge has been determined and where it has been found $p(v)=\exp (-$ $\left.v / v_{0}\right)$, which leads in turn to a distribution of speed $\rho(v)$ in the gas bulk varying as $\rho(v)=$ $[A /(v S)] \exp \left(-v / v_{0}\right)$ since $p(v)=v S \rho(v)$ (where $S$ is the gauge surface). Also, in this previous experiment the speed $v_{0}$ has been found to vary as $N^{0.4}$ It seems that both experiments compare relatively well, since they both get an exponential distribution, while they slightly differ due to the $1 / v$ pre-factor in the Airbus results. We have no explanation for not getting this pre-factor here; it might be due to the little accuracy of the speed measurement at slow speed. However, the curvature of the distribution $\rho(v)$ which is observable at low speed in Figure 6 may result from the existence of this pre-factor.

The above results prove that the velocity distribution follows the distribution $\exp \left(-v / v_{0}\right)$, which is a nonBoltzmann function, i.e. $\exp \left(-v^{2} / v^{2}\right)$. Hence they provide another evidence for a "velostat" rather than "thermostat" boundary conditions in dilute granular gas system $[8,9]$ in this concentration range. In other words this shape of distribution may come probably from the fact that ball collisions preserve the sum of momenta rather than the sum of kinetic energies [8].

At last it is interesting to note that similar exponential trend has been found recently using simulation [10] in some other configuration, as soon as one includes solid friction and rotation.

\section{ACKNOWLEDGMENTS}

This work is supported by grant Nos. 10720101074 , 10874209 and KKCX1-YW-03. PE \& YG want to thank CNES \& ESA for funding and assistance.

\section{REFERENCES}

1. (i) Falcon E., Aumaître S., Evesque P., Palencia F., Lecoutre-Chabot C., Fauve S., Beysens D.\& Garrabos Y., Europhys. Lett. 74, 830- (2006); (ii) Leconte M., Garrabos Y., Falcon E., Lecoutre C., Palencia F., Evesque P., Beysens D., Journal of Statistical Mechanics: Theory and experiment, P07012 (2006).

2. Falcon E., Wunenburger R., Evesque P., Fauve S., Chabot C., Garrabos Y., Beysens D., "Cluster formation in a granular medium fluidised by vibrations in low gravity", Phys. Rev. Lett. 83, 440-443 (1999).

3. McNamara S. and Young W.R., Phys. Fluids A 4, 496 (1992).

4. Poschell T. \& Luding S., Granular Gases, Lectures Notes in Physics 564, Springer-Verlag, Berlin, (2001).

5. Poschel T. and Brilliantov N. V., Granular Gas Dynamics, Lectures Notes in Physics 624, SpringerVerlag, Berlin, (2003).

6. (i) Goldhirsch I., Rapid granular flow, Annu. Rev. Fluid Mech. 35, 267 (2003); (ii) Barrat A., Trizac E. \& Ernst M.H., arXiv:cond-mat/0411435 v2, 3/12/2004, J. Phys. C 17, S2429 (2005).

7. Leconte M., Garrabos Y., Palencia F., Lecoutre C., Evesque P., Beysens D., Appl. Phys. Lett. 89, 243518 (2006 ).; Evesque P., Palencia F., Lecoutre-Chabot C., Beysens D. and Garrabos Y., Microgravity Sci. Technol. XVI-1, 280-284 (2005).

8. (i) Evesque P., Poudres \& Grains 14 (2) pp 8-53 (Mai 2004); (ii) Evesque P., poudres \& grains 15 (1) pp 1-16 (février 2005).

9. Evesque P., Poudres \& Grains 13 (2) pp 20-26 (2003).

10. A. Kawarada \& H. Hayakawa, J. Phys. Soc. Jpn. 73, $2037(2004)$

11. W. Losert, D. G. W. Cooper, J. Delour, A. Kudrolli and J. P. Gollub, Velocity statistics in excited granular media, Chaos 9,682 (1999)

12. J.Javier Brey \& M. J. Ruiz-Montero, Velocity distribution of fluidized granular gases in the presence of gravity, Phys. Rev. E 67, 021307 (2003)

13. Sung Joon Moon, J. B. Swift \& Harry L. Swinney, Steady-state velocity distributions of an oscillated granular gas, Phys. Rev. E 69, 011301 (2004)

14. M. Hou, R. Liu, G. Zhai, Z. Sun, K. Lu, Y. Garrabos \& P. Evesque, Microgravity Science \& Technology 20, pp 73-80 (2008) 